\title{
Performance and Growth Analysis of Three Mungbean (Vigna Radiate (L.) Wilczek) Genotypes at Hawassa, Ethiopia
}

\author{
Melese Lema*, Bililign Mekonnen and Getachewu Gudero \\ Department of plant breeding, Southern Agricultural Research Institute, Ethiopia
}

Submission: June 06, 2018; Published: September 11, 2018

*Corresponding author: Melese Lema, Southern Agricultural Research Institute (SARI), Department of plant breeding. P.O Box: 06, Hawassa Ethiopia, Tel: +251910057232, Email: meleselema72@gmail.com

\begin{abstract}
The experiment was conducted during 2017 at the compound of Hawassa University in the College of Agriculture, Southern Ethiopia during off cropping season. To investigate the performance of different mung bean varieties on response of different growth parameters such as Specific Leaf Area, Leaf area ratio, net assimilation rate, and Relative growth and total dry Biomass. Three mung bean cultivars were grown in randomized complete block design with three replications. The objective of the study was to assess the performance of mung bean cultivars in relation to growth parameters and to estimate the analysis of growth characteristics using the primary values generated from these cultivars. Data were specific leaf area ratio, leaf area ratio, net assimilation rate, relative growth rate and above ground biomass. There is significant difference among cultivars observed for total dry biomass. The SLA and LAR of all cultivars increment from first sample to second sample as crop development progressed. The highest SLA and LAR were attributed suniana variety. Gofa local cultivar is highest total dry biomass, since in this study genetic factor and environment are a key factor for achieving optimum growth and dry matter production of mung bean cultivars.
\end{abstract}

Keywords: Leaf area ratio; Mung bean varieties; Net assimilation rate; Performance; Relative growth; Specific Leaf Area and total dry biomass

Abbreviations: LA: Leaf Area; CGR: Crop Growth Rate; NAR: Net Assimilation Rate; RGR: Relative Growth Rate; TDM: Total Dry Matter

\section{Introduction}

Mungbean (Vigna radiata (L.) Wilczek) Mungbean belongs to the order Leguminosae and Papilionoideae family [1]. It is an important short duration, self-pollinated diploid legume crop with high nutritive values and nitrogen fixing ability. Hence, it is an eco-friendly food grain leguminous crop of dry land agriculture with rich source of proteins, vitamins, and minerals [2]. Mungbean contains $51 \%$ carbohydrate, $24-26 \%$ protein, $4 \%$ mineral, and $3 \%$ vitamins [3]. Besides providing protein in the diet, mungbean has the remarkable quality of helping the symbiotic root rhizobia to fix atmospheric nitrogen and hence to enrich soil fertility [4]. Smallholder farmers in drier marginal environments in Ethiopia grow mung bean. In southern Ethiopia, Farmers in some moisture stress areas (Gofa, Konso, south Omo zone and Konta) have been producing mung bean to supplement their protein needs and also effectively use scanty rainfall [5]. However, its agricultural productivity is drastically limiting in Ethiopia due to low genetic diversity and even if there are some genotypes, they are not improved genotypes [6]. This factor making the mung bean unknown to all farmers of the country and its production is being limiting. However, some researchers have been done they are describes morphological diversity of the crop which might not exactly isolate superior genotypes for the farmers.
Several reports have been made about the contribution of various yield components towards yield [7,8]. The yield components depend on some physiological traits. To understand the physiological basis of yield difference among the genotypes of mungbean, it is essential to quantify the components of growth, and the variation, if any, may be utilized in crop improvement. Variation in dry matter accumulation and pod production in different genotypes may be related to some factors such as leaf area (LA), crop growth rate (CGR), net assimilation rate (NAR) and relative growth rate (RGR). Mondal et al. [9] analyzed growth parameters of six varieties of Mungbean to study the physiological causes of yield differences and observed differences in CGR, NAR, RGR and LA among the varieties. Not only total dry matter (TDM) production, the capacity of efficient partitioning between the vegetative and reproductive parts may produce high economic yield. A better understanding of crop growth, yield parameters and the partitioning of assimilates into seed formation would help to expedite yield improvement of field crops and mungbean genotypes recent report showed in this regard $[10,11]$ in different countries but not in Ethiopia. Hence, the present study was undertaken with the following objectives. 


\section{Objectives}

i. To enables us understanding how data collected, analyzed and see impacts of different growth characteristics using the primary value generated from these three genotypes.

ii. To assess the performance of mungbean genotypes in relation to growth parameters.

\section{Material and Methods}

\section{Description of the Study Area}

The experiment was conducted during 2017 cropping season at Hawassa university college of Agriculture research field. Hawassa is found in southern parts of Ethiopia. The area is located $6^{\circ} 42^{\prime} \mathrm{N}$ and $38^{\circ} 29^{\prime} \mathrm{E}$ and with an elevation of 1650 masl. The soil of experimental area was fertile and sandy loam soil with $\mathrm{PH}^{\mathrm{H}}$ of 5.5. The average mean annual rain fall is $800 \mathrm{~mm}$ with an average annual minimum and maximum temperature of 13 and $27^{\circ} \mathrm{C}$, respectively. The research was done by supplementary irrigation since there was shortage of rain fall during sowing time. The lab experiment was conducted at the department of plant and horticultural Sciences in the Physiology laboratory.

\section{The Experimental Material and Design}

The experiment was conducted using two improved and one local mungbean genotypes. These are Sunian, MH-97-6 and Gofa local (local check). The experiment was conducted using Randomized Complete Block Design (RCBD) replicated three times. The seeds were sown in plant spacing $40 \times 10 \mathrm{~cm}$, plot size $-2 \mathrm{~m} \times 2 \mathrm{~m}$, each plot had 5 rows with total area $4 \mathrm{~m}^{2}$, since $08 / 03 / 2017$. Seeds were drilled and thinned after fully ground cover. Supplementary irrigation took place immediately after sowing and the seed was emerged or fully seen after 7 days from sowing. Except experimental variables all other non-experimental variables and agronomic field management practices were applied uniformly to each plot and maximum care was taken to minimize the possible occurrence of yield limiting factors.

Data Collected: The first and the second samples were taken after 29 and 57 days from sowing, respectively and for both sample, 3 plants were taken at random from the middle row for each plot to determine the following characters (primary values): plant height $(\mathrm{cm})$, leaves area $\left(\mathrm{cm}^{2}\right)$, dry weights of stems and leaves (gm). The final sample was taken 65 days after emergence by harvesting Two middle rows of mung bean population plants (area $1.6 \mathrm{~m}^{2}$ ) for each plot which was important to determine or measure total dry matter (TDM) $\left(\mathrm{g} / \mathrm{m}^{2}\right)$. Besides, there are other materials used to facilitate in data collection. These are sickle for harvesting, sensitive balance for actual measuring of the weights, portable area meter for leaf area measurement and others, subjected to dry over an oven at $70^{\circ} \mathrm{C}$ for 48 hours. Then the growth analysis like Specific leaf area (SLA), Leaf area ratio (LAR), Relative growth rate (RCR) and net assimilation rate (NAR) were carried out following the formula: -

\section{Specific leaf area (SLA)}

Where SLA is specific leaf area $\left(\mathrm{cm}^{2} \mathrm{~g}^{-1}\right)$, A is leaf area $\left(\mathrm{cm}^{2} \mathrm{~m}^{-2}\right)$ and $\mathrm{W}_{\text {leaf }}$ is leaf dry weight $\left(\mathrm{gm}^{-2}\right)$

$$
S L A=\frac{A}{W_{\text {leaf }}}
$$

Leaf area ratio (LAR)

$$
L A R=\frac{A}{W}
$$

Where LAR is leaf area ratio $\left(\mathrm{cm}^{2} \mathrm{~g}^{-1}\right)$, A is leaf area $\left(\mathrm{cm}^{2} \mathrm{~m}^{-2}\right)$ and $\mathrm{W}$ is plant dry weight $\left(\mathrm{gm}^{-2}\right)$

Relative growth rate (RGR)

$$
R G R=\left(\frac{\left(\ln W_{2}-\ln W_{1}\right)}{\left(T_{2}-T_{1}\right)}\right)
$$

Where RGR is relative growth rate $\left(\mathrm{mgg}^{-1} \mathrm{day}^{-1}\right)$,

$\mathrm{W}_{1}, \mathrm{~W}_{2}=$ subscripts 1 and 2 indicate the value of $\mathrm{W}$ (plant dry weight) on two occasions $\left(\mathrm{gm}^{-2}\right) \mathrm{T}_{1}, \mathrm{~T}_{2}=$ subscripts 1 and 2 indicate consecutive samplings at time $\mathrm{T}_{2}$ and $\mathrm{T}_{1}$.

Net assimilation rate (NAR)

$$
N A R=\frac{\left(W_{2}-W_{1}\right)\left(\ln A_{2}-\ln A_{1}\right)}{\left(A_{2}-A_{1}\right)\left(T_{2}-T_{1}\right)}
$$

Where, $\mathrm{W}_{1}$ and $\mathrm{W}_{2}$ are the $\mathrm{DM}$ at the time $\mathrm{T}_{1}$ and $\mathrm{T}_{2}$ respectively. LA1 and LA2 are leaf area at the time $\mathrm{T}_{1}$ and $\mathrm{T}_{2}$, respectively.

Data Analysis: Each growth parameters were analyzed and computed mean values \pm SE (standard error) by using the above listed formula for each treatment (genotypes). The recorded data of the mungbean genotypes for dry weight biomass was subjected to Analysis of Variance (ANOVA) appropriate to the experimental design analyzed using SAS software version 9.1 and tested significance at $5 \%$ probability level using the $\mathrm{F}$ test.

\section{Result and Discussion}

\section{Growth Parameters}

Specific Leaf Area: Specific leaf are is a measurement of leaf thickness which plays an important role in leaf and plant functioning and related to species' strategies of resources acquisition and use related with dry matter accumulation. Results of this experiment indicated that there were differences between three varieties with $108.35 \mathrm{~cm}^{2} / \mathrm{g}, 85.62 \mathrm{~cm}^{2} / \mathrm{g}$ and $103.03 \mathrm{~cm}^{2} / \mathrm{g}$ for sunian, MH-97-6 and Gofa local respectively within two sampling times (Table 1). The numerical values told that variety sunian had better leaf thickness which enables assimilate highly. This show that the resources (water) contribute for good uptake of for the formation of high dry matter and this study agree with Ann B. The SLA of all cultivars increased as crop development progressed. But the differences in SLA among the cultivars were 
relatively small. The SLA of sunian was better than MH-97-6 and in both sampling date and better than Gofa local at second sample. Highest specific leaf area of a crop indicates that it has larger leaf area, and this helps the crop to have highest efficiency of light harvesting which means higher photosynthetic rate. SLA is an important trait characterizing plant adaptation to environmental conditions: its plasticity is often seen as a way for plants to increase the efficiency of light-harvesting, and/or the efficiencies of resource-use (e.g., light, water and nitrogen-use efficiencies).

Table 1: Growth Analysis on the Specific Leaf Area (SLA), Leaf Area Ratio (LAR).

\begin{tabular}{|c|c|c|c|c|}
\hline \multirow[t]{2}{*}{ Trt } & \multicolumn{2}{|c|}{ 1st Sample } & \multicolumn{2}{|c|}{ 2nd Sample } \\
\hline & $\operatorname{SLA}_{1}\left(\mathrm{~cm}^{2} \mathrm{~g}^{-1}\right)$ & $\operatorname{LAR}_{1}\left(\mathrm{~cm}^{2} \mathrm{~g}^{-1}\right)$ & $\operatorname{SLA}_{2}\left(\mathrm{~cm}^{2} \mathrm{~g}^{-1}\right)$ & $\operatorname{LAR}_{2}\left(\mathrm{~cm}^{2} \mathbf{g}^{-1}\right)$ \\
\hline Sunaina & $60.80787 \pm 9.514$ & $46.58474 \pm 7.981653$ & $155.8889 \pm 16.69473$ & $90.69486 \pm 10.41097$ \\
\hline MH-97-6 & $58.28 \pm 7.194091$ & $43.8528 \pm 3.38598$ & $112.9627 \pm 35.45205$ & $66.84819 \pm 18.92605$ \\
\hline Goffa-L & $72.16019 \pm 0.792059$ & $51.45253 \pm 0.806804$ & $133.895 \pm 9.441825$ & $76.05607 \pm 4.675801$ \\
\hline
\end{tabular}

*First Sampling at 22 days after emergence and Second sampling at 50 days after emergence

SE: Standard Error; SLA1: Specific Leaf Area First Sampling; SLA2: Specific Leaf Area Second Sampling; LAR1: Leaf Area Ratio First Sampling; LAR2: Leaf Area Ratio Second Sampling

Leaf Area Ratio (LAR): The ratio between leaf area and total plant dry weight has been termed the leaf area ratio (LAR). A high LAR has been considered a desirable characteristic because it indicated the plant had a high photosynthetic potential in relation to its respiratory load. The yields of bean cultivars were more highly correlated with their LAR than with either their LAI. The LAR of all cultivars increased as crop development progressed. This result argued that decline. But the differences in LAR among the cultivars were relatively high. The LAR of Sunian was better than MH-97-6 and Gofa local with the mean values of 68.6398, 55.35 and 63.75 respectively. All cultivars showed a great increment in LAR. Compared several dry bean cultivars and found the yields were highly and positively correlated with the LAR. On the other hand, a negative relationship between the grain yields of soybean cultivars and their LAR values. The results of the present study from the yield and biomass relationship agree with those of Wallace and Munger (Table 2).

Table 2: Growth Analysis on Net Assimilation Rate (NAR) and Relative Growth Rate (RGR).

\begin{tabular}{|c|c|c|c|c|c|c|c|}
\hline Trt & LWR1 (gg-1) & LWR2 $\left(\mathrm{gg}^{-1}\right)$ & NAR $\left(\mathrm{mg} \mathrm{dm}^{-2}\right)$ & $\begin{array}{l}\text { RGR (mgg-1 } \\
\left.\text { day }^{-1}\right)\end{array}$ & $\operatorname{LAI1}\left(\mathrm{cm}^{-2}\right)$ & LAI2 $\left(\mathrm{cm}^{-2}\right)$ & $\begin{array}{c}\text { CGR (gm-2 } \\
\left.\text { day }^{-1}\right)\end{array}$ \\
\hline Sunaina & 0.775 & 0.580769 & 49.5 & 56 & $0.000535 \pm 6.456153$ & $0.006555 \pm 30.91489$ & 0.0000595 \\
\hline MH-97-6 & 0.773585 & 0.636145 & 2.3 & 66.5 & $0.000645 \pm 6.39799$ & $0.006885 \pm 42.06054$ & 0.000111 \\
\hline Goffa-Local & 0.711111 & 0.570588 & 59 & 64.4 & $0.000641 \pm 3.191812$ & $0.007215 \pm 41.0635$ & 0.0000803 \\
\hline Mean \pm SE & \pm 0.021 & \pm 0.02 & \pm 17.532 & \pm 3.208 & & & \pm 0.000014 \\
\hline
\end{tabular}

Net Assimilation Rate (NAR): Net assimilation rate has been defined as the rate of increase of dry weight per unit of leaf area. This parameter has frequently been calculated in field research to estimate the photosynthetic efficiency of crop leaves. Donald pointed out that the NAR value for a crop was an average value for all leaves. From table3 result showed Sunain high NAR than MH-97-6 and Gofa local. Several studies have found a negative correlation between leaf area ratio and NAR the rate of decline in LAR per unit increase in NAR has been used as a measure of the canopy efficiency of crops. The NAR of improved cultivars showed a slower rate of decline than the older standard ones. They attributed this to improvements of canopy architecture. Cultivars with a higher LAR would have a higher NAR, also; this experimental results in line with relationship. They found that SLA had a high heritability and suggested it would be a good characteristic for easy, indirect selection of photosynthetic efficiency.

Relative Growth Rate (RGR): Relative growth rate is the rate of increase in plant dry weight relatively to the total dry weight of that plant. The relative RGR of the cultivars depended on the stage of crop development Table 3. During the period, between two samples date, the RGR of MH-97-6 was better than Sunian and Gofa local numerically. The correlation between LAR, the ratio between total leaf area and total plant weight, and RGR was very high. This positive correlation was mainly due to the SLA, the ratio between leaf area and leaf weight, and to a lesser extent caused by the leaf weight ratio, the fraction of plant biomass allocated to the leaves. Table 3 the mean separation for biomass dry weight.

Table 3: Means with the same letter are not significantly different.

\begin{tabular}{|c|c|c|}
\hline Treatment & Mean & Grouping \\
\hline Gofa local & 767.033 & $\mathrm{~A}$ \\
\hline Suniana & 695.0833 & $\mathrm{~B}$ \\
\hline MH-97- & 569.625 & $\mathrm{C}$ \\
\hline
\end{tabular}

$\mathrm{LSD}=10.6$

\section{Above Ground Dry Weight Biomass}

The above ground total biomass showed significant difference for Gofa local from suniana and MH-97-6 mung bean cultivars with the mean values 767.0833, 695.5833 and 569.625, respectively (Table 3). Leaf dry weight was the major component of the total dry weight. Dry matter accumulation in crops has a 
direct relationship with leaf area ratio. The LSD shows their significant difference between treatments that means varieties has a positive effect on total dry matter. This implies that genetic and environmental effect is to difference dry matter accumulation. From Table 4 result shows that Gofa local is the highest Total dry biomass than Suniana and MH-97-6 varieties.

Table 4: A Nova for Final Harvest Biomass Dry Weight (Above Ground).

\begin{tabular}{|c|c|c|c|c|c|}
\hline $\begin{array}{c}\text { Source of } \\
\text { Variation }\end{array}$ & DF & SS & MS & F cal & $\begin{array}{c}\text { F tab } \\
\mathbf{5 \%}\end{array}$ \\
\hline Rep & 2 & 4340.566 & 2170.283 & 0.477651 NS & 6.94 \\
\hline Trt & 2 & 251064.7 & 125532.4 & $27.62804^{*}$ & 6.94 \\
\hline Error & 4 & 18174.63 & 4543.658 & & \\
\hline Total & 8 & 273579.9 & & & \\
\hline
\end{tabular}

$\mathrm{CV}=9.9 \% \mathrm{CV}=$ Coefficient of Variation

\section{Summary and Conclusion}

The genetic and environmental factors can cause a different level of variation of the tested characteristics of mung bean varieties. Because yield is a complex trait resulting from the interaction of morphological, phonological physiological and environmental parameters on the growth of plants, Mung bean (Vigna Radiate (L.) Wilczek). Cultivar types are important for good agronomic performance for greater growth and total dry biomass showed in the studied area. The SLA and LAR of all cultivars increased and positively correlated as crop development progressed in first and second sapling. During the period, between samples 1 and 2, the SLA of Suniana was better than MH-97-6 and Gofa local the same result for LAR. During the period, between two sampling dates, the RGR of MH-97-6 was better than Sunian and Gofa local numerically. As it is shown on the result, when relative growth rate increase leaf area ratio and specific leaf area also increases. So, it's possible to conclude that both leaf area ratio and specific leaf area affect the Mung bean growth rate. The above ground total dry biomass showed significant difference Gofa local from MH-97-6 and Sunaina Mung bean cultivars. Numerically the maximum biomass $767.0833 \mathrm{gm} / \mathrm{m}^{2}$ from Suniana 695.5833 $\mathrm{gm} / \mathrm{m}^{2}$ and $569.625 \mathrm{gm} / \mathrm{m}^{2}$ from MH-97-6. Therefore, response of growth and growth parametrs of the performance mung bean cultivars in the study area lead us to the conclusion different genetic capacity for its biomass production among cultivars. Generally, it is fair to say that these Mung bean cultivars perform differently across their growing period.

\section{References}

1. Rachie KO, Roberts LM (1974) Grain legumes of the lowland tropics. Adv Agron 26:1-132.

2. Ketinge J, Easdown W, Yang A, Chadh R, Shanmugasundaram MS (2011) Performance and Growth Analysis of Three Mungbean (Vigna Radiate (L.) Wilczek) Genotypes at Hawassa, Ethiopia. Euphytica, 180: 129-141.

3. Afzal MA, Murshad AN, Bakar MA, Hamid A, Salahuddin ABM (2008) Mungbean Cultivation in Bangladesh, Pulse Research Station, Bangladesh Agricultural Research Institute, Gazipur, Bangladesh.

4. Anjum MS, Ahmed ZI, Rauf CA (2006) Effect of Rhizobium inoculation and nitrogen fertilizer on yield and yield components of mungbean. International Journal of Agriculture and Biology 8(2): 238-240.

5. Asrate Asfawu, Fikadu Gurmu, FistumAlemayehu, Yayis Rezene (2012) Analysis of Multi-environment Grain Yield Trials in Mung Bean Vigna radiate (L.) Wilczek Based on GGE Bipot in Southern Ethiopia. J. Agric. Sci. Tech. 14: 389-398.

6. Itefa Degefa (2016) General Characteristics and Genetic Improvement Status of Mung bean (Vigna radiata L.) in Ethiopia Review Article. International Journal of Agriculture Innovations and Research 5(2): 2319-1473.

7. Hassan MS, Siddique AK, Malek MA (1995) Correlation studies in mungbean. Bangladesh Journal of Agricultural Research. 20: 126-131.

8. Singh SK, Singh IP, Singh BB, Singh O (2009) Correlation and path coefficient studies for yield and its components in mungbean. Legume Research 32(3): 180-185.

9. Mondal MMA, Puteh AB, Malek MA, Ismail MR, Rafii MY, et al. (2012) Seed Yield of Mungbean (Vigna radiata (L.)Wilczek) in relation to Growth and Developmental Aspects. Scientific World Journal 2012: 425168 .

10. Khan A. and Khalil S.K. 2010. Effect of leaf area on dry matter production in aerated mungbean seed. Int. J. Plant Physiol and Biochem. 2(4):5261.

11. Hozayn M, Zeidan M, Abd El-Lateef E, Abd El-Salam M (2007) Performance of some mungbean (Vignna radiate L. Wilczek) genotypes under Late Sowing Condition in Egypt. Research Journal of Agriculture and Biological Sciences 6: 972-978.

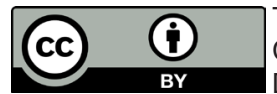

This work is licensed under Creative Commons Attribution 4.0 License DOI: 10.19080/CTBEB.2018.16.555940

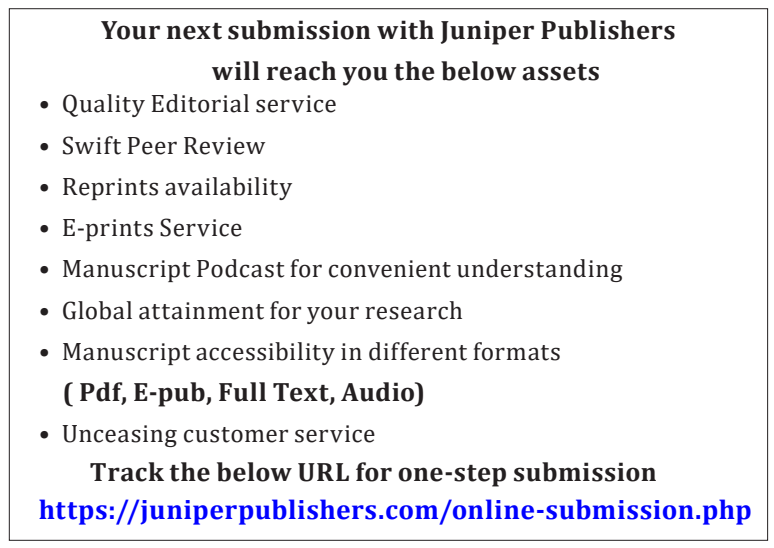

